\title{
Hacia una teoría urbana transmoderna y decolonial: una introducción
}

\author{
Yasser Farrés Delgado \\ Dpto. de Filosofía, Universidad de Zaragoza, Zaragoza, España. \\ Email: yasserfarres@gmail.com
}

\begin{abstract}
Alberto Matarán Ruiz
Dpto. de Urbanismo y Ordenación del Territorio, Universidad de Granada, Granada, España. Email: mataran@ugr.es
\end{abstract}

\begin{abstract}
Resumen: Este artículo defiende que los impactos globales de las tendencias de homogenización y pérdida de identidades en arquitectura, urbanismo y ordenación del territorio sólo serán superados si se reconocen como parte de la occidentalización del mundo y si se promueve una actitud decolonial que conduzca a la teoría urbano-arquitectónica hacia la "transmodernidad" mediante una "ecología de saberes" que incluye a las experiencias marginadas por el pensamiento moderno. En ese sentido se presenta un enfoque crítico basado en la "colonialidad territorial".

Palabras clave: colonialidad territorial, transmodernidad, actitud decolonial teoría de la arquitectura, teoría del urbanismo.
\end{abstract}

\section{Towards an urban transmodern and decolonial theory: an introduction}

\begin{abstract}
This paper argues that the global impacts caused by the homogenisation and loss of identity tendencies in architecture and planning will be only overcome if recognizing them as part of the world westernization and if a decolonial attitude is promoted for leading the urban-architectural theory through "transmodernity" by means of the "ecology of knowledge" including the experiences that modern thinking marginalized. In that sense, the paper presents a critical approach based on "territorial coloniality".
\end{abstract}

Key words: territorial coloniality, transmodernity, decolonial attitude, theory of architecture, urban theory.

\section{Rumo a una teoria urbana transmoderna e descolonial: uma introdução}

Resumo: Este artigo argumenta que os impactos globais das tendências de homogeneização e perda de identidade na arquitetura, urbanismo e ordenamento do território serão superados somente se reconhecidos como parte da ocidentalização do mundo e seé promovida uma atitude descolonial que conduz à teoria urbana e arquitetônica para a "transmodernidade" por meio de uma "ecologia de saberes", 
que inclui as experiências marginalizadas pelo pensamento moderno. Nesse sentido se apresenta uma abordagem crítica com base na"colonialidade territorial".

Palavras-chave: colonialidade territorial, transmodernidade, atitude descolonial, teoria da arquitetura, teoria do urbanismo.

$* * *$

\section{Múltiples actitudes respecto a la praxis dominante}

Entrada la segunda década del siglo XXI la necesidad de una profunda revisión de las teorías urbanas que dominan la práctica profesional es cada vez más evidente. Lo sugiere la incontable información que existe sobre los nefastos impactos sociales, ambientales y económicos de la práctica generalizada; datos que demuestran que una parte de la teoría desarrollada en el siglo XX está obsoleta y superada por la complejidad de la realidad, como explican Montaner y Muxí (2011: 211). O como ilustran Taylor y Lang (2004), quienes luego de identificar cien términos distintos sobre la nuevas formas metropolitanas y las nuevas relaciones entre ciudades, concluyen que la invención de concepto tras concepto difícilmente conduzca a un entendimiento creíble de qué está pasando en y entre las ciudades, y además, que el predominio de adjetivos como global, internacional, mundial o transnacional justifica repensar la tradición teórica en urbanismo porque es inoperante para la nueva escala de los fenómenos.

La necesidad de revisar las teorías existentes se puede vislumbrar observando las tendencias globales de homogenización y pérdida de identidades que dominan la praxis arquitectónica, urbana y territorial generalizada en las principales urbes del planeta. Esos procesos han sido criticados por décadas — ya en 1927 Ludwig Hilberseimer alertaba que las grandes ciudades crecían sin planificación en beneficio de la especulación privada, que sus poderes traspasaban la economía nacional para alcanzar la economía mundial, y que se parecían tanto entre sí que podía hablarse de la internacionalización de su aspecto (Hilberseimer, 1999: 1-3) —; sin embargo la comunidad profesional todavía los niega o responde con escepticismo, como se verá más adelante. Estas actitudes no deberían sorprender porque los debates teóricos alrededor de la década de 1950, que condicionaron la extinción de los CIAM, ya señalaban el carácter homogeneizador del funcionalismo generalizado pero este continuó reproduciéndose.

Comparar las principales urbes actuales descubre la tendencia hacia un proceso de reproducción de tipologías referidas entre sí globalmente pero con pocos referen $\neg$ tes que las asocien a una cultura o un territorio local específico, fenómeno reconocible por la presencia de cierta arquitectura caracterizada por una estética abstracta de supuesta validez universal, “supermoderna” (Ibelings, 1998), o en su defecto, otra “urBANAL” (Muñoz, 2008) que “fetichiza” y vacía de contenido a las imágenes del pasado.Ambas estéticas suelen responder a los intereses de capitales transnacionales dando forma a hoteles, centros de negocios, puertos deportivos y muchos 
otros programas que, insertados cual reclamo publicitario en áreas urbanas específicas a "resucitar" de forma segregada, contrastan con el abandono de otras zonas de la ciudad marcadas por la marginalización social (Muxí, 2004). Precisamente, esa relación evidencia que la homogenización y la pérdida de identidades no refieren sólo a los aspectos tipológicos y estéticos de las ciudades sino también a dimensiones sociales, culturales, económica y otras.

Para tener idea de la dimensión global de estos procesos de homogeneización y pérdida de identidades sirve comparar las metrópolis contemporáneas que son referentes globales con aquellas que existían por el mundo previo a la expansión colonialista occidental: se apreciará que en los modelos de antaño existía una diversidad tipológica difícilmente alcanzada por los actuales. De hecho, las tipologías arquitectónicas, urbanas y territoriales de la Europa medieval cristiana dife $\neg$ rían tanto de sus contemporáneas islámicas, orientales y mesoamericanas (o del Gran Zimbabwe, que pocos libros sobre arquitectura universal documentan); todas diferían tanto entre sí; cada grupo respondía tan específica $\neg$ mente a factores físicoambientales, técnico-económicos y socioculturales; que hoy se pueden reconocer relaciones biunívocas muy particulares entre cada tipología de asentamiento y la cosmovisión de cada sociedad. Por ello no es casual que puedan ofrecerse clasificaciones como las que aportó Chueca Goitía (1968) para destacar las diferencias entre la «ciudad pública» heredera de la tradición romana, la «ciudad doméstica» y campestre de la tradición nórdica y la «ciudad privada» y religiosa del Islam.

¿Puede decirse que en el contexto del sistema-mundo actual, dominado por la cosmovisión moderna y desarrollista occidental, existe una diversidad homóloga? ¿Puede decirse, cuando las condiciones físicas, ambientales locales o los límites de las tecnologías autóctonas ya no son restricciones para reproducir los modelos globales porque la transferencia tecnológica, la exportación de materiales constructivos y el uso de la energía fósil sirven para eliminarlas (no sin generar nuevos problemas)?

A pesar de todo lo dicho, habrá quienes respondan a estas preguntas con un rotundo sí. Es la expresión más radical laactitud moderna, influida por la línea filosófica que Jürgen Habermas representó en la Bienal de Arte de Venecia de 1980 (donde por primera vez se incluía la arquitectura dentro de la muestra), cuando afirmó que la modernidad es un proyecto inacabado (Habermas, 1997). Este grupo de profesionales buscará argumentos que reafirmen las particularidades de las metrópolis contemporáneas llegando a dos extremos: 1) la supervaloración de las cuestiones inmateriales vinculadas a la vida; ó 2) el énfasis de las cuestiones tipológicas de la ciudad o el espacio geográfico. Representativo de lo primero es Edward Glaeser en “El triunfo de las ciudades”. Este autor afirma:

“(Entre las ciudades) son los fracasos los que se parecen entre sí, mientras que los éxitos siempre tienen algo de singular. Alguien que recorriera los barrios de Leipzig, llenos de viviendas desocupadas y 
con las ventanas tapadas por tablones, podría muy bien creer que está en Detroit. (...) Sin embargo, nadie podría confundir jamás Bangalore con Boston, o Tokio con Chicago. Las ciudades prósperas siempre desprenden una abundancia de energía humana que se expresa de formas distintas y define su propio espacio idiosincrásico. (...) En Tokio y Singapur (...) hay torres altas y franquicias, pero ninguna de estas dos ciudades tiene la menor semejanza con Hong Kong ni se parecen entre sí. Mientras Hong Kong es una ciudad decididamente multicultural, Tokio es una ciudad profundamente japonesa dotada de una sensibilidad especial que a los extranjeros les resulta muy difícil comprender. Singapur es una ciudad aún más abierta a los occidentales que Hong Kong, pero sus calles están menos concurridas y sus reglas son mucho más estrictas. En las tres ciudades se come de maravilla, pero (...) (nadie) confundiría el atún crudo con el pato a la cantonesa o esa mezcla multiétnica que hace que degustar la cocina de Singapur sea una experiencia tan deliciosa” (Glaeser, 2011: 309-310).

Caso representativo de lo segundo, que interesa citar por ser influyente en España, es el argumento que Manuel de Solá Morales defendía en el Congreso Internacional de la UIA de Barcelona en 1996:

"No creo que las ciudades, por el hecho de tener autopistas, sean todas necesariamente iguales que Tokio o que Los Ángeles o que cualquier otro modelo único (...) Al fin y al cabo habría que ver dónde están los hechos significativos en la forma de las ciudades (...) Algún arquitecto importantísimo y conocedor de las ciudades ha descrito, por ejemplo, que hoy día las ciudades todas son como Atlanta, como Singapur y como Los Ángeles. Bueno, entre Atlanta, Singapur y Los Ángeles hay enormes diferencias. Es que no se parecen en nada a poco que uno las conozca. Sería bueno comprobar su experiencia sobre estas ciudades. Yo, sin conocerlas mucho, las conozco lo suficiente como para ver que realmente, a pesar de que todas han experimentado un boom edificatorio tremendo durante los últimos años, una explosión de autopistas, y que tienen todas ellas un sistema espacial fragmentado y descompuesto, eso no debiera bastarnos para pensar que son iguales. Porque, con este criterio, también cabría decir que todas las ciudades del pasado eran idénticas porque se componían de calles y edificios, de plazas y paseos. $\mathrm{O}$ sea, no matizar algo sobre estas cosas nos puede llevar a simplificaciones peligrosas y a perder la noción de lo que nuestro oficio puede aportar al futuro de las ciudades.” (Solá-Morales, 2004: 99-100)

En clara oposición a esas posturas existe otro grupo de profesionales que responderá rotundamente "No". Es la actitud posmoderna en la línea de Christopher Alexander (1977) o de Krier (2010), Kunstler (2010) o Duany (2003) y otras personas que representan el New Urbanism estadounidense, quienes defienden el valor de las estructuras urbanas y arquitectónicas tradicionales al punto de copiarlas casi literalmente. 
Una posición intermedia responderá que no existe una variedad tipológica como la de antaño pero puede alcanzarse si se replantea la modernidad reconsiderando el valor de las tradiciones (aunque se niega caer en la mimesis posmoderna). Este es el caso de la actitud regionalista, emergida de los debates culturales poscoloniales y recogida por Kenneth Frampton (1985) como regionalismo crítico, que en el contexto latinoamericano se respaldan teóricamente en conceptos como "transculturación”, ofrecido en 1940 por elcubano Fernando Ortiz (2002), o “hibridez”, desarrollado más recientemente por el argentino Néstor García Canclini (2001), los cuales plantean la posibilidad de una modernidad "propia” o "apropiada”, esto es, diferentes "modernidades". También parece ser el caso de la actitud territorialista, cuyo más conocido teórico es el arquitecto y urbanista italiano Alberto Magnaghi, quien se sirve del postestructuralismo de Gilles Deleuze y Félix Guattari y sus ideas sobre el capitalismo como máquina desterritorializadora (cf. Deleuze y Guattari, 1987) para argumentar la existencia de un proceso global de “desterritorialización de la metrópoli” como consecuencia de la modernización (Magnaghi, 2012), pero no niega rotundamente que existan elementos recuperables de la modernidad que puedan retomarse junto a las lógicas tradiciones para crear nuevas formas de poblamiento más apropiadas.

La actitud de la Escuela Territorialista Italiana es particularmente interesante a los efectos de renovar la teoría urbana porque se nutre de críticas al proyecto moderno provenientes de distintas disciplinas (el paradigma ambiental, la participación ciudadana, la teoría del decrecimiento...) que atienden a una serie de dimensiones que están más allá de lo estético o formal (aspectos económicos, sociales, culturales, etcétera). En ese sentido, se trata de generar nuevos modelos de poblamiento capaces de revitalizar el territorio de las hipotrofias de las megalópolis siguiendo las reglas productivas y reproductivas del lugar para conducir necesariamente a la autosostenibilidad del sistema territorial local, lo que exige producir nuevas territorialidades "poniendo en relación virtuosa y sinérgica la producción de valor territorial añadido (sostenibilidad económica) con el aumento de la capacidad de autogobierno (sostenibilidad política), el crecimiento en complejidad e integración del sistema decisional (sostenibilidad social), y con la implementación de reglas de ocupación y de producción que generen nuevos equilibrios ambientales (sostenibilidad ambiental)" ' (Magnaghi, 2012: 91-106).

Con esta visión tan amplia la actitud territorialista muestra, sin duda alguna, potencialidades para abrazar a lasotras actitudes fundadas en la diversidad (cultural, de género, de capacidades física, de diferencias etarias), algunas de las cuales aun permanecen marginadas dentro de una academia renuente a aceptarlas, que constituyen, como explican Montaner y Muxí (2011), «nuevas epistemologías» capaces de dotar a los procesos de diseño con herramientas apropiadas tanto para gestionar la incertidumbre que hoy envuelve a "lo urbano" como para restaurar los nefastos impactos sociales, ambientales y económicos generalizados. 
No es intención establecer aquí una clasificación definitiva de todas las actitudes en relación con la teoría urbana dominante, y muchos menos valorar cada una. Interesa, más bien, destacar tres conclusiones preliminares: 1) la confluencia de todas esas actitudes demuestra la actualidad de la discusión epistémica entorno a la negación/reafirmación del proyecto civilizador moderno; 2) la discusión epistémica no puede plantearse al margen del carácter global de los problemas mencionados; y 3) la diversidad de actitudes desvela la necesidad de atender múltiples dimensiones del hecho urbano. Considerándolas, se propone a continuación debatir la teoría urbana contemporánea desde la perspectiva de la modernidad/colonialidad; traer a estas áreas específicas del conocimiento un debate general propuesto desde ese pensamiento crítico latinoamericano acerca de la crisis de legitimidad del conocimiento moderno y su impacto mundial.

Como se mostrará, este enfoque es capaz de integrar todos los elementos positivos de cada una de las distintas actitudes en relación con el proyecto de la modernidad. El término “colonialidad” hace pensar directamente en "colonialismo” — guarda relación, de hecho_-; pero no es lo mismo. Tampoco trata asuntos que sólo interesan a las sociedades poscoloniales. Lejos de eso, describe actitudes imperiales en los procesos de conocimientos generados en las ex metrópolis, ya sean estos conservadores o progresistas.

\section{La perspectiva de la modernidad/colonialidad como marco para analizar la teoría urbana: la colonialidad territorial}

La perspectiva de la modernidad/colonialidado "crítica decolonial” se ha ido conformando a partir de los señalamientos que hizo el sociólogo peruano Aníbal Quijano (1991), desde la noción “colonialidad del poder”, a la “teoría del sistema-mundo moderno”propuesta antes por el sociólogo estadounidense Immanuel Wallerstein (1974, 1979). Se trata de un enfoque que pone de relieve el rol fundamental de la expansión colonial hispánica en laconformación epistémica de la modernidad y desvela el eurocentrismo del proyecto civilizatorio globalizado. Esta propuesta quedó formalmente validada cuando ambos autores unieron sus puntos de vista (Quijano \& Wallerstein, 1992). De hecho, el propio Wallerstein (1997; 2006) ha continuado desarrollándola.

En esencia, la crítica decolonial plantea que tras el fin del colonialismo y las administraciones coloniales se ha consolidado un sistema-mundo donde la epistemología occidental domina sobre el resto de las epistemologías; hegemonía fundada en una historia imperial de larga duración que construyó al hombre occidental como sujeto de enunciación superior y patrón de supuesta validez universal, sustento filosófico por el que Occidente ha dictado y pretende seguir dictando las normas de toda existencia humana mundial. Para comprender esta perspectiva debe quedar claro que «colonialismo» $\mathrm{y}$ «colonialidad» no son lo mismo. Como indica 
Quijano (2001), mientras «colonialismo» denota una relación política y económica en la que la soberanía de una nación o pueblo descansa en el poder de otra nación, lo que convierte a esta última en imperio, «colonialidad» refiere, en cambio, a un conjunto de patrones de poder de larga duración que emergieron con el colonialismo pero definen la cultura, las relaciones intersubjetivas, la distribución del trabajo y la producción de conocimientos más allá de los estrictos límites de las administraciones coloniales. Sobre esas diferencias Ramón Grosfoguel apunta:

“El colonialismo es más antiguo que la colonialidad (...) Lo nuevo en el mundo moderno-colonial es que la justificación de dicha dominación y explotación colonial pasa por la articulación de un discurso racial acerca de la inferioridad del pueblo conquistado y la superioridad del conquistador" (Grosfoguel, en Montes y Busso: 2007)"

Nelson Maldonado-Torres (2007: 243) agrega sobre esto que la colonialidad se mantiene tan viva en los libros, en los criterios para el desempeño académico, en los patrones culturales, el sentido común, la autorepresentación de las personas, las aspiraciones del yo y tantos otros aspectos de la experiencia moderna que, como sujetos modernos, «respiramos colonialidad todo el tiempo y cada día».

Recientemente Ramón Grosfoguel aclaró que la palabra “colonialidad” estaba dicha antes por otras personas, como las feministas chicanas, y que la idea se encontraba en las formulaciones del pensamiento africano (Kwame Nkhruma) y negro en las Américas (véase Frantz Fanon, Aimé Cesaire, W.E.B.Dubois, Angela Davis, Sylvia Wynter, Abi Dias Nascimento, Cedric Robinson, etcétera) aunque usaran otros términos. Quijano, usando “colonialidad del poder”, aporta una manera nueva de nombrar esa articulación entre raza y otras relaciones de poder, lo que ayuda a entender y distinguirla de la palabra colonialismo (ver MARTÍNEZ ANDRADE, 2013)

La “crítica decolonial” está estrechamente relacionada con los “estudios poscoloniales” pero se nutre de otras genealogías de pensamiento y, por tanto, mantiene diferencias sustanciales en cómo concibe la relación entre «modernidad» y «colonialidad». Los estudios poscoloniales, que emergen de una crítica al eurocentrismo hecha por intelectuales de Asia Occidental y el sur de Asia (cf. Said, 1979; Spivak, 1988; Bhabha, 1994), relacionan la colonialidad con la expansión imperialista británica y francesa en aquellas áreas durante el siglo XIX, postura que, ontológicamente hablando, deja intacto el discurso tradicional según el cual la modernidad es un proceso autónomo europeo iniciado durante el siglo XVII como parte de la Ilustración (pues la colonialidad sería una condición posterior). La crítica decolonial, en cambio, afirma que los fundamentos ontológicos de la modernidad están en el debate filosófico que la conquista española de América produjo acerca de la naturaleza humana de las poblaciones autóctonas. Así, la colonialidad y la modernidad son dos caras de una misma moneda (Mignolo, 1995; 2002). 
Esta es la tesis que expone Enrique Dussel (1992, 1996, 2008) cuando explica que la significación del ego cogito cartesiano para la modernidad es consecuencia de un incuestionable ideal del yo expresado en la noción ego conquiro (el "yo conquistador”) que en el proceso de colonización construyó al "otro no-europeo" como sujeto inferior; lo que puede reconocerse en las consecuencias históricas del debate que mantuvieron Bartolomé de las Casas y Juan Ginés Sepúlveda en Valladolid entre 1550 y1551 acerca de la condición humana de los nativos americanos. Quiere decir esto, como explica Grosfoguel (2008) siguiendo a Dussel, que la renovación respecto al estancado pensamiento escolástico medieval no la inicia el ego cogito solipsista y dualista cartesiano, supuestamente capaz de llegar al conocimiento desde un monólogo interior, sino la relación que el "yo conquistador" establece con el "otro conquistado".

Siguiendo el argumento de Dussel, Grosfoguel (2008, 2008b) demuestra que el ego conquiro está en la base del concepto de "universal" desde Descartes hasta Marx pasando por Kant y Hegel, y que incluso llega a la noción de "imperio" de Hardt y Negri (2001) pasando por la idea del"imperialismo como fase superior del capitalismo"que expuso Lenin (1916); lo que significa que, desde la modernidad hasta la posmodernidad, ha existido un discurso histórico eurocéntrico y lineal tanto en los fundamentos del proyecto de civilización global de "la derecha” como en el proyecto emancipador global de "la izquierda eurocéntrica”. Al respecto Santiago Castro-Gómez (2005) ya había apuntado varios elementos, analizando “el punto ciego” de Marx sobre la cuestión latinoamericana y “el capítulo faltante del Imperio” en la visión de Hart y Negri, que demuestran cómo la colonialidad y el eurocentrismo persisten en la posmodernidad/poscolonialidad que no cuestiona las jerarquías epistémicas occidentales. Por todo ello puede hablarse de una "colonialidad global” (Mignolo, 2000) articulada a través de una estructura triangular entre "la colonialidad del saber”, "la colonialidad del ser", y “la colonialidad del poder" ejercidas desde el privilegio epistémico occidental (Castro-Gómez, 2007).

A partir de varios autores y autoras, intelectuales chicanas y feministas negras (Moraga y Anzaldua, 1983; Collins 1990) e intelectuales del tercer mundo dentro y fuera de los Estados Unidos (Dussel, 1977; Mignolo, 2000), Grosfoguel (2006) explicaba las relaciones entre el ego conquiro y el ego cogito que subyacen en el sujeto de enunciación moderno; cuyos conocimientos, supuestamente objetivos, neutrales, universales y válidos para todas las personas, responden en realidad al modelo de hombre blanco, europeo, capitalista, militar, cristiano, patriarcal y heterosexual. Grosfoguel apunta que la jerarquía epistémica del sujeto de enunciación occidental en el sistema-mundo moderno/colonial se evidencia en múltiples manifestaciones, de las cuales identifica las siguientes catorce:

1) una formación de clase global particular donde van a coexistir y organizarse una diversidad de formas de trabajo (esclavitud, 
semiservidumbre, trabajo asalariado, producción mercantil-simple, etc.) como fuente de producción de plusvalía mediante la venta de mercancías para obtener ganancias en el mercado mundial;

2) una división internacional del trabajo del centro y la periferia donde el capital organizaba el trabajo en la periferia alrededor de formas represivas y autoritarias (Wallerstein, 1974);

3) un sistema interestatal global de organizaciones político-militares controladas por hombres europeos e institucionalizadas en administraciones coloniales (Wallerstein, 1979) y, más adelante, neo-coloniales;

4) una jerarquía étno/racial global que privilegia a los occidentales sobre los no-occidentales (Quijano, 1993; 2000);

5) una jerarquía global de género que da primacía a los hombres sobre las mujeres y al patriarcado europeo sobre otras formas de relaciones de género (Spivak, 1988; Enloe, 1990);

6) una jerarquía sexual que otorga primacía a los heterosexuales sobre los homosexuales y lesbianas (es importante recordar que la mayoría de los pueblos indígenas en América no consideraban que la sexualidad entre hombres fuera una conducta patológica y no tenían, antes de la llegada de los europeo, una ideología homofóbica); 7) una jerarquía espiritual global que da primacía a los cristianos sobre las espiritualidades no-cristianas/no-occidentales institucionalizada en la globalización de la iglesia cristiana (católica y más tarde protestante);

8) una jerarquía epistémica que privilegia al conocimiento y la cosmología occidentales sobre el conocimiento y las cosmologías no-occidentales, y está institucionalizada en el sistema universitario global (Mignolo, 1995, 2000; Quijano, 1991).

9) una jerarquía lingüística entre las lenguas europeas y las no-europeas que hace primar la comunicación y la producción teórica y de conocimiento en los primeros, subalternizando los últimos como productores de folclor o cultura solamente pero no de conocimiento ni teoría (Mignolo, 2000).

10) una jerarquía estética global donde se privilegian las formas de belleza y gustos occidentales y se inferiorizan las formas de belleza y gustos no-occidentales institucionalizado en los Ministerios de Cultura y en la jerarquía de museos y galerías artísticas globales así como en los diseños mercantiles industriales.

11) una jerarquía pedagógica global donde se privilegian las pedagogías occidentales de matriz cartesiana sobre las pedagogías nooccidentales institucionalizado en el sistema escolar mundial.

12) una jerarquía de medios de comunicación global donde se privilegian los aparatos de comunicación controlados por occidente.

13) una jerarquía ecológica global donde se privilegia el concepto de « naturaleza » occidental (donde la naturaleza es siempre pasiva, exterior a los humanos y un medio para un fin) con todas las consecuencias nefastas para el medio ambiente/ecología planetaria y se descartan otras formas de entender el medio ambiente y la ecología (donde las personas son parte de la ecología y la "naturaleza" es un 
fin en sí mismo). El concepto occidental lleva la lógica de la destrucción ecológica pues al pensar la naturaleza como medio para un fin, toda la tecnología que construye lleva dentro de sí la racionalidad de la destrucción ecológica y no la de su reproducción.

14) una jerarquía de edad occidentalizada donde se privilegia la edad adulta-productiva entre los 16 y 64 años inferiorizando y haciendo dispensables a los “viejos” y los “niños”.

A la luz de los procesos los procesos globales de homogenización y pérdida de identidad descritos al inicio del artículo, puede afirmarse que esas jerarquías guardan estrechas relaciones con la configuración de los espacios de la vida humana, palpable en la reproducción de los modelos arquitectónicos, urbanos y territoriales generalizados por la globalización. De hecho, no es casual que las actitudes mencionadas se preocupen por algunos de esos puntos, si bien ninguna elabora un discurso teórico y metodológico que enlace a todos ellos. De ahí que existan, por ejemplo, posturas ambientalistas que no toman en cuenta la validez del conocimiento que los enfoques de género aportan sobre la cuestión ambiental (precisamente, una de las razones de ser del ecologismo feminista), y también, otras que no cuestionan el lugar de enunciación privilegiado del científico respecto al ciudadano. Este último es el caso de la "ciencia del modo" (Gibbons et al., 1997), enfoque que respalda las necesidades y demandas de la ciudadanía pero los individuos, comunidades y culturas que representan el saber experto no científico están lejos de poseer un rol activo en la producción de conocimiento (Hessels \& Lente, 2008).

Para establecer conexiones entre los aspectos positivos de las distintas actitudes, la propuesta en el presente trabajo promover una actitud decolonial que siga la perspectiva de la modernidad/colonialidad y analice como parte de las consecuencias del privilegio de la episteme occidental las tendencias de homogenización y pérdida de identidades antes descritas. En este sentido, interesa retomar la propuesta de Farrés y Matarán (2012) que define la colonialidad territorial como el conjunto de patrones de poder que en la praxis territorial sirven para establecer hegemónicamente una concepción del territorio sobre otras que resultan "inferiorizadas". Se trata de una particularización del concepto general que ofrece Castro-Gómez (2007) sobre colonialidad, y que permite hablar de la especificidad de la estructura triangular entre la colonialidad del ser territorial, la colonialidad del saber territorial y la colonialidad del poder territorial (Figura1). 


\section{Figura. 1 El triángulo de la colonialidad territorial como particularidad de la estructura triangular de la colonialidad.}

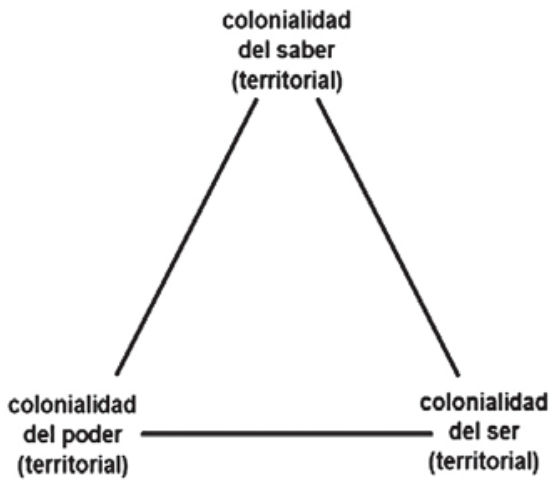

Fuente: Farrés y Matarán 2012.

Como indican los autores, múltiples hechos prueban la existencia del triangulo de la colonialidad territorial. Por ejemplo, puede afirmarse que la colonialidad del ser territorial está dada por la hegemonía que el "ser-urbano" tiene sobre el resto de las formas de existencia humana no-urbanas ("ser no-urbano"), consolidada con la actual organización de la sociedad mundial a través de la publicidad para la compra y venta de pisos o casas, las burbujas inmobiliarias, las notables diferencias en la remuneración de las actividades productivas agrícolas sobre las no agrícolas y otros mecanismos que fomentan esa hegemonía. Que la población mundial sea cada vez más urbana, lo constata: vivir, es cada vez más sinónimo de vivir en la ciudad.

Por su parte, la colonialidad del saber territorial ha sido establecida en las propias prácticas profesionales donde ciertos saberes dominan en las decisiones respecto a cómo concebir y habitar el territorio, la ciudad y la arquitectura. Muestras de ello son: el privilegio con que las disciplinas científicas universalizan nociones occidentales de territorio, ciudad y arquitectura; la exportación de los patrones occidentales de vida urbana; la propia jerarquía otorgada al "ser urbano"sobre el "ser no-urbano"como modelo de existencia; o la subvaloración que la enseñanza del diseño urbano-arquitectónico generalizada hace de lo tradicional, vernáculo o popular como respuesta válida a los problemas actuales.

En cuanto a la "colonialidad del poder territorial”, definida siguiendo a Mignolo (2000) comoel ámbito de la intersubjetividad en que cierto grupo de gentes define qué es territorialmente correcto y, por lo tanto, sustentan el poder de enunciación; esta se ejerce tanto en los escenarios territoriales globales como en los locales. En los primeros, ostentan poder de enunciación agentes transnacionales como los monopolios de la explo- 
tación de los recursos naturales o de la construcción, algunas fundaciones, organismos internacionales y otros. En los segundos, lo hacen los gobiernos locales y otros actores con poder de decisión, aunque cada vez más influidos por los agentes transnacionales pues no existe desconexión entre una escala y otra.

La discusión epistémica, filosófica, metodológica, práctica, política, sociológica... que promueve la crítica decolonial sobre el carácter eurocéntrico de la modernidad y la posmodernidad, tiene clara implicaciones para las disciplinas de la arquitectura, el urbanismo y la ordenación del territorio y la actuación sobre sus objetos de estudio (el ambiente construido, el paisaje, la arquitectura, la ciudad, el territorio, el medioambiente...) porque abre un espacio para idear teorías sobre aspectos poco explorados de la realidad urbana y su racionalidad. En ese sentido no puede negarse el papel hegemónico de la episteme occidental en la conformación de un sistema-mundo cada vez más urbanizado; no pueden negarse las relaciones entre el universalismo de la filosofía cartesiana y la arquitectura y el urbanismo modernos de Le Corbusier; entre el estructuralismo y las propuestas de Reiner Bahman, Team X, Archigram o los Metabolistas Japoneses; entre el relativismo posmoderno y la arquitectura de Aldo Rossi, Robert Venturi, o Philip Johnson; entre el posestructuralismo “derridiano” y la arquitectura deconstructivista de Peter Eisenman, Zaha Hadid o Bernad Tshumi; o entre el racionalismo "habermasiano” y la arquitectura supermoderna de Herzog \& De Meuron.

Todas esas tendencias no sólo plantean concepciones fundadas en la posición privilegiada de las ex metrópolis dentro de la cartografía histórica del poder global sinoson exportadas como ideas de vanguardia hacia las academias occidentalizadas de los países poscoloniales, que terminan reproduciéndolas. De hecho, puede decirse que son eurocéntricos los debates que esa importación ha despertadoen y sobre Latinoamérica pues la reflexión sobre cómo integrarse a la propuesta modernizadora global se articula, como norma general, respecto a una noción de identidad nacional (base del regionalismo crítico que señala Keneth Frampton) que es más una revisión de la tradición occidental en América (la arquitectura portuguesa hispánica, francesa e inglesa en las colonias) que una apuesta por revalorizar las concepciones espaciales, estéticas y constructivas propias de las culturas autóctonas.

Este debate latinoamericano no está cerrado, como explicara Eliana Cárdenas (1998: 99-120), y la perspectiva decolonial ofrece nuevas pistas para repensarlo. No es intención agotarlas aquí pero interesa destacar, por ejemplo, que incluso en países con una importante tradición arquitectónica prehispánica como es el caso de México, las tendencias urbanas y arquitectónicas desde el siglo XIX hasta la primera mitad del siglo XX en que irrumpe el Movimiento Moderno, están fuertemente influidas por lo que ocurre en Europa y EEUU. En el caso mexicano, explica Eliana Cárdenas citando a Rafael López Rangel (1989), los arquitectos ligados a oligarquía porfiriana llegaron a alentar el eclecticismo europeo como expresión de modernidad y 
“puesta al día” de la nación argumentando que, la arquitectura nacional, sólo puede producirse cuando existe nación, y no existía una nación "mexicana” en los períodos prehispánicos. Al respecto López Rangel (1989:1921) destacauna pregunta de Nicolás Mariscal: “¿Hemos de tener por nuestras las llamadas arquitecturas maya, tolteca, azteca o zapoteca, desarrolladas cuando ni aún existíamos no como raza, no como nación?”.

\section{Transmodernidad y pluriversalismo como horizontes para una teoría urbano-arquitectónica posabismal}

El portugués Boaventura de Sousa Santos, uno de los intelectuales europeos que ha entrado en diálogo con la teoría de la modernidad/ colonialidad latinoamericana, describe los impactos del pensamiento moderno occidental en términos que suenan drásticos pero reflejan bien la realidad. Para este autor:

"El pensamiento occidental moderno es un pensamiento abismal. Éste consiste en un sistema de distinciones visibles e invisibles, las invisibles constituyen el fundamento de las visibles. Las distinciones invisibles son establecidas a través de líneas radicales que dividen la realidad social en dos universos, el universo de "este lado de la línea” y el universo del "otro lado de la línea”. La división es tal que "el otro lado de la línea" desaparece como realidad, se convierte en no existente, y de hecho es producido como no existente. No existente significa no existir en ninguna forma relevante o comprensible de ser. Lo que es producido como no existente es radicalmente excluido porque se encuentra más allá del universo de lo que la concepción aceptada de inclusión considera es su otro. Fundamentalmente lo que más caracteriza al pensamiento abismal es pues la imposibilidad de la copresencia de los dos lados de la línea. Este lado de la línea prevalece en la medida en que angosta el campo de la realidad relevante. Más allá de esto, sólo está la no existencia, la invisibilidad, la ausencia no dialéctica.” (Sousa Santos, 2010: 11-12)

Sousa Santos utiliza el concepto "línea abismal” para explicar que la modernidad ha convertidoen "desechos culturales" a todas aquellas experiencias no-occidentales negándoles la posibilidad de existir; es decir, que ha producido un“epistemicidio"en el cual la ciencia moderna se concede a sí misma el privilegio epistemológico y destruye «todos los conocimientos alternativos que podrían venir a enjuiciar ese privilegio» (Sousa Santo, 2003:276).Siendo así, urge desarrollar un "pensamiento posabismal” que rompa radicalmente los modos occidentales modernos de pensar y actuar, y que confronte la "monocultura de la ciencia moderna" con una"ecología de los saberes"que reconozcala pluralidad de conocimientos heterogéneos (la ciencia moderna entre ellos) y las interconexiones continuas y dinámicas que existen entre unos y otros sin comprometer cada autonomía. Es decir, un pensamiento ecológico que revalorelas otras intervenciones en el mundo real más allá de la productividad tecnológica de la ciencia moderna (Sousa 
Santos, 2010); situación que no puede producirse dentro de la posmodernidad porque está llena de "estereotipos norcéntricos respecto al Sur" donde "la celebración de la fragmentación, de la pluralidad y de la proliferación de las periferias oculta una relaciona desigual, central en el capitalismo moderno (...) que a menudo combina la crítica del universalismo occidental con una reivindicación de la singularidad de occidente” (Santos, 2006:41).

Inicialmente Sousa Santos (2003) habló depromover un “posmodernismo de oposición” frente al "posmodernismo celebratorio"dominante que, centrado en la deconstrucción y la exaltación de la contingencia, abandona la tarea de pensar alternativas a lo que se critica (postura que él identifica en trabajos como los de Derrida y Baudrillard). Posteriormente, en su aproximación a la perspectiva de la modernidad/colonialidad, Sousa Santos acoge la idea de "transmodernidad", que acuña Enrique Dussel para describir una situación epistémica global productora de diálogos horizontales y liberadores entre los conocimientos críticos producidos tanto fuera como dentro de la modernidad eurocentrica.

Como explica Grosfoguel (2006), la transmodernidad es el proyecto utópico que Dussel (2001) opone al de Habermas (1997), y plantea que en lugar de completar una modernidad centrada en Europa e impuesta como un diseño global al resto del mundo debe abogarse por una multiplicidad de respuestas críticas decoloniales desde las culturas subalternas y el lugar epistémico de los pueblos colonizados en todo el mundo.De este modo, sigue explicando Grosfoguel,la transmodernidad sería equivalente a la “diversalidad como proyecto universal” que resultaría de la intervención epistémica desde los subalternos diversos (Mignolo, 2000). Las epistemologías subalternas podrían proporcionar, siguiendo al redefinición que hace Mignolo (2000) del concepto del pensador caribeño Edward Glissant, una "diversalidad" de respuestas a los problemas de la modernidad que conduciría a "la transmodernidad".

La transmodernidad implica establecerun "pluri-versalismo" en oposición al "uni-versalismo" que restringe la capacidad de universalidad a la tradición occidental (Mignolo 2000; Grosfoguel 2007), abrir la universidad al libre concurso de actores y agentes poseedores de saberes y conocimientos expertos; articular una producción del saber libre, inclusiva y descentrada (Pageau 2010) estableciendo nuevas estrategias de producción del conocimiento (Carrizo et al, 2004) que pongan en común y en diálogo tanto los saberes académicos como los saberes tradicionales y locales. Esa es la clave de la descolonización del saber, y no significa discutir la validez del conocimiento científico sino cuestionar su hegemonía y exclusividad (Castro-Gómez (2007).

Este debate decolonial sobre la hegemonía del conocimiento occidental y el proyecto moderno, respecto a cuyas grandes promesas puede afirmarse que «aún están por ser cumplidas, o que su cumplimiento ha terminado por precipitar efectos perversos» (Sousa Santos, 2006:18), po- 
dría parecer ajeno a la teoría urbana; sin embargo, las tendencias globales de homogenización y pérdida de identidades sugieren lo contrario. Tanto es así que, si se analizan esas tendencias como un fenómeno de larga duración producto de la occidentalización del mundo, puede afirmarse que a partir de 1492 ha existido un epistemicidio de saberes territoriales, urbanos y arquitectónicos que desde entonces impacta sobre los conocimientos ancestrales en los territorios colonizados pero a partir del siglo XX ha terminado afectando a las propias tradiciones europeas. De hecho, recuérdese que el Movimiento Moderno produjo un distanciamiento de las realidades culturales preexistentesfavorecido por la conveniente apropiación que, los arquitectos más influyentes, hicieron del concepto historicista del Zeitgeist para justificar una afirmación antihistórica hecha en falso: construir una propia genealogía moderna a costa de negar los precedentes históricos y apropiarse del sentido de la historia negándolo al mismo tiempo, yrespaldada por un andamiaje historiográfico que justificó la actuación de los arquitectos vanguardistas mostrándoles como "héroes míticos que se enfrentaban al enemigo de la decadencia” (Montaner, 1999: 35). Ese distanciamiento lo reproducen en la posmodernidad los arquitectos (y muy pocas arquitectas) del star system global, cuyas arquitecturas de autor pretenden tener marcas propias con independencia de los contextos locales.

Es decir, que lo ocurrido en estas esferas específicas del quehacer humano demuestra materialmente las consecuencias epistémicas de la modernidad y posmodernidad descritas por los intelectuales, hombres y mujeres de distintas procedencias y culturas, que se adscriben al "programa de investigación de la modernidad/colonialidad” (Castro-Gómez y Grosfoguel, 2007). Reconocer esta realidad de la praxis territorial, urbana y arquitectónica generalizada abre un campo adondedeberían entrar las teorías y metodologías de estas disciplinas para contribuir a descolonizar "el ser territorial”, “el saber territorial” y “el poder territorial”, y promover así nuevas epistemologías urbanas, posabismales, pluriversas, transmodernas y decoloniales en diálogo con "las ausencias" y "las emergencias" correspondientes.

Si se considera que Sousa Santos se refiere por "desechos culturales” a lo que Mignolo (2000), aludiendo a las experiencias producidas por el otro (los otros y las otras) en la frontera del conocimiento del yo moderno (es decir, como exterioridad relativa respecto a la modernidad), llama "pensamiento fronterizo", "pensamiento otro" o "gnosis frontera”; se podrá comprender, entonces, que esas nuevas epistemologías urbanas deben promover una justicia epistémica hacia "las ausencias"esas otras concepciones sobre la existencia espacio/temporal que tambiénforman parte de lo que Victor M. Toledo y Narciso BarreraBassols (2008) llaman “memoria biocultural”.

Esa revalorización ya está teniendo lugar, al menos teóricamente, en los criterios que manejan las nuevas constituciones de Bolivia (2007) y Ecuador (2008) para incorporar el "buen vivir" (sumak kawsayen lengua quechua ysuma qamaña en aymara) como eje articulador de sus 
cartas magnas (Roa Avedaño, 2009). En el caso del Estado Plurinacional de Boliviala revaloración de las territorialidades originarias y la noción deaylluo comunidad (Prada, 2008), ha permitido considerar a la pachamama (madre tierra) como un sujeto de derecho; posibilidad inaceptable dentro de la racionalidad dominante en la arquitectura, el urbanismo, la ordenación del territorio y el planeamiento regional occidental es que, consecuentes con el "desencantamiento del mundo"producido por la ciencia moderna (Weber, 2002), asumen un manejo objetual del paisaje/territorio.

A la luz de los procesos de homogenización y pérdida de identidades, ¿̇no son estos ejemplos un camino (no el único, ni el único para todas las personas) que, basado en los principios y valores de un grupo humano (cosmovisión), aporta una alternativa viable en la búsqueda de formas del ser territorial porque las personas mantienen su identidad y conviven en armonía con la naturaleza? Precisamente las principales contradicciones que en la práctica frenan el desarrollo de esas experiencias, residen en la persistencia de una racionalidad occidental que se exige mantener un modelo basado en cuestionables políticas "extractivistas" y la construcción de impactantes infraestructuras; todo ello en consonancia con un concepto de desarrollo que, como explica Serge Latouche (2007), sólo existe en la mentalidad occidental.

Las nuevas epistemologías urbanas también deben promover una justicia epistémica hacia "las emergencias" que existen fuera de los espacios técnico-académicos institucionalizados (universidad, centros de investigación, oficinas de diseño, etc.), producidas por la acción ciudadana y el activismo, y siguiendo a Alberto Magnaghi (2011) pueden reconocerse como "energías insurgentes". Ellas ameritan reconocimiento porque también generan procesos de identificación, pertenencia al lugar, cohesión social y sostenibilidad. Asimismo, se ha de integrar esa "parte de la cultura arquitectónica y del urbanismo contemporáneos digna y rescatable” que recogen Montaner y Muxí (2011); o las que definen nuevos horizontes al urbanismo y generan nuevos "territorios inteligentes”, como exponen Vergara y De la Rivas (2004). De no producir ese reciclaje cognitivo tan sólo se estaría invirtiendo la posición de la "línea abismal”, a favor de las ausencias, y reproduciendo lógicas del fundamentalismo epistémico occidental.

La inclusión tanto de "las ausencias" como "las emergencias" debe reconocer, en cualquier caso, que ninguna de ellasaporta una visión completa de la realidad (son inconmensurables); pero debe partir de que, como explica Sousa Santos (2010: 31-44), sí es posible establecer comunicaciones e insospechadas formas de complementariedad dependiendo del uso de procedimientos adecuados de traducción intercultural que permitan identificar tanto las preocupaciones comunes y los enfoques complementarios como, por supuesto, las contradicciones intratables. 


\section{Conclusiones}

Este artículo no pretende concluir con “una nueva” teoría urbana o "un nuevo" método de trabajo como proyectos universalistas para el urbanismo, sino reivindicando la necesidad de una «actitud decolonial» en relación con la crítica a los procesos de homogenización y pérdida de identidad en la praxis arquitectónica, urbana y territorial que abra espacios dentro de la academia para las «teorías urbanas otras» que no son "nuevas" sino que han permanecido en una marginalidad producto de la colonialidad ejercida por los saberes hegemónicos a pesar de que han existido y sustentado la generación de otras concepciones espaciales tanto fuera de la modernidad (epistemologías espaciales ausentes) como dentro de esta (epistemologías emergentes).

Esta conclusión no es un mero juego intelectual posmoderno: apunta a descolonizar la jeraquía epistémica occidental reconociendootros paradigmas que escapan a la "racionalidad" moderna, otros sistemas de conocimientos (tecnológicos, estéticos, perceptivos, simbólicos...), que no sólo acumulan extensas experiencias (muchas veces milenarias) sino que, lejos de ser históricos, tradicionales, folklóricos, vernáculos, kitsh.... (adjetivos utilizados por la historiografía de la arquitectura y el urbanismo para colocarles por debajo de la línea abismal marcada unilateralmente por los intelectuales de la modernidad), son actuales porque, frente al problema totalmente contemporáneo que son las insostenibles tendencias globales de la praxis dominante, aportan alternativas de poblamiento humano ecológicas y con identidad. Esta apertura supone redefinir y ampliar la gnosis de "lo urbano", que ha de ser vista de forma sistémica, transdisciplinaria e intercultural para acabar con la colonialidad territorial. 


\section{Nota}

${ }^{1}$ Se podría decir que la Escuela Territorialista Italiana nace a mediados de los años ochenta del siglo XX, y que centra su atención disciplinar en el territorio como bien común en función de su identidad histórica, cultural, social, ambiental, y productiva considerando al paisaje como su manifestación sensible. En este grupo convergen personas estudiosas que se autodenominan "topofílicas” y que proceden de diversas disciplinas, entre otras: urbanismo, arquitectura, diseño, ecología, geografía, antropología, sociología, historia, economía, ciencias ambientales, geofilosofía, agronomía, arqueología, etc. En el 2012 se fundó en Florencia la Sociedad Territorialista Italiana (www.societadeiterritorialisti.it) que trata de promover la colaboración entre territorialistas de diversas disciplinas y está orientada a la relación entre los múltiples enfoques existentes en torno a las ciencias del territorio. 


\section{Bibliografía}

Alexander, Christopher; Ishikawa, Sara; Silverstein, Murray et al (1977), A pattern language: towns, buildings, construction. Oxford University Press, New York.

Bhabha, Hommi (1994), The location of culture. Routledge, Nueva York.

Cárdenas, Eliana (1998), Problemas de teoría de la arquitectura. Universidad de Guanajuato, México.

Carrizo, L.; Espina Prieto, Mayra; y Klein, Julie T. (2004), Trandisciplinariedad y Complejidad en el Análisis Social. Cuaderno de Debate $\mathrm{n}^{\circ} 70$, Programa MOST. UNESCO, París.

Castro-Gómez, Santiago (2005), La poscolonialidad explicada a los niños. Editorial Universidad del Cauca, Instituto Pensar, Pontificia Universidad Javeriana, Popayán.

Ídem (2007), “Descolonizar la Universidad. La hybris del punto cero y el diálogo de saberes”. En: Castro-Gómez, Santiago y Grosfoguel, Ramón, El giro decolonial: reflexiones para una diversidad epistémica más allá del capitalismo global. Siglo del Hombre Editores, Bogotá.

Castro-Gómez, Santiago y Grosfoguel, Ramón (2007), “Prólogo. Giro decolonial, teoría crítica y pensamiento heterárquico”. En, Castro-Gómez, Santiago y Grosfoguel, Ramón, El giro decolonial: reflexiones para una diversidad epistémica más allá del capitalismo global. Siglo del Hombre Editores, Bogotá.

Collins, Patricia Hill (1990), Black Feminist Thought: Knowledge, Consciousness and the Politics of Empowerment. Routledge, Chapman and Hall, Nueva York.

Deleuze, Gilles y Guattari, Felix (1987), A Thousand Plateaus. Capitalism and Schizophrenia. The University of Minnesota Press, Minneapolis:

Duany, Andrés; Plater-Zyberk, Elizabeth; Krieger, Alex (2003), Práctica del post-suburbanismo. Ediciones Unión, La Habana.

Dussel, Enrique (1977), Filosofía de Liberación. Edicol, México.

Ídem (1992), 1492: El encubrimiento del Otro. Hacia el origen del mito de la Modernidad. Nueva Utopía, Madrid.

Ídem (1996), The Underside of Modernity: Apel, Ricoeur, Rorty, Taylor and the Philosophy of Liberation. Humanities Press, New Jersey.

Ídem (2001), Hacia una Filosofía Política Crítica. Desclée de Brouwer 
Bilbao, España.

Ídem (2008), "Meditaciones anticartesianas: sobre el origen del anti-discurso filosófico de la modernidad”, Tabula Rasa 9, 153-197.

Enloe, Cynthia (1990), Banana, Beaches and Bases: Making Sense of International Politics. University of California Press, Berkeley.

Farres, Yasser; Mataran, Alberto (2012), “Colonialidad territorial: para analizar a Foucault en el marco de la desterritorialización de la metrópoli. Notas desde la Habana”, Tabula Rasa 16, 139-159

Frampton, Kenneth (1985), “Towards a critical regionalism: six point for an architecture of resistances”. En Foster, H (ed.), The anti-aesthetic. Essays on posmodern culture. Pluto Press, Londres.

García Canclini, Néstor (2001), Culturas híbridas. Estrategias para entrar y salir en la modernidad. Paidos Ibérica, Buenos Aires.

Gibbons, Michael; Limoges, Camille; Nowotny, Helga et al (1997), La nueva producción del conocimiento: la dinámica de la ciencia y la investigación en las sociedades contemporáneas. Ediciones Pomares-Corredor.S.A, Barcelona.

Glaeser, Edward (2011), El triunfo de las ciudades: cómo nuestra mejor creación nos hace más ricos, más inteligentes, más ecológicos, más sanos y más felices. Taurus, Madrid.

Grosfoguel, Ramón (2006), “La descolonización de la economía política y los estudios postcoloniales. Transmodernidad, pensamiento fronterizo y colonialidad global”, Tabula Rasa 4, 17-48.

Ídem (2008), “Hacia un pluri-versalismo transmoderno decolonial”, Tabula Rasa 9, 199-215

Ídem (2008b), “Del imperialismo de Lenin al Imperio de Hardt y Negri: ‘fases superiores’ del eurocentrismo”, Universitas Humanística 65, 15-26.

Habermas, Jürgen (1997), “Modernity: an unfinished project”. En Benhabib, Seyla \& Passerin D’Entreves, Maurizio (ed.), Habermas and the Unfinished Project of Modernity: Critical Essays on The Philosophical Discourse of Modernity. MIT Press, Cambridge.

Hardt, Michael; Negri, Antonio (2001), Imperio. Ediciones Desde Abajo, Bogotá.

Hessels, L. K.; Lente, H. (2008), “Re-thinking new knowledge production: A literature review and a research agenda”. Research Policy 37, 740-760. 
Hilberseimer, Ludwig (1999), La arquitectura de la gran ciudad. Ed. Gustavo Gili, Barcelona.

Ibelings, Hans (1998), Supermodernismo. Arquitectura en la era de la globalización. Ed. Gustavo Gili,Barcelona.

Krier, Léon (2010), Arquitectura: elección o destino adverso. Teoría del nuevo urbanismo. Ediciones Unión, La Habana.

Kunstler, James Howard (2010), Meditaciones sobre la condición problemática del Nuevo Urbanismo. Ediciones Unión, La Habana.

Latouche, Serge (2007), Sobrevivir al desarrollo. Icaria, Barcelona.

Lenin, Vladimir I. (1970), El Imperialismo. Fase superior del Capitalismo. Editorial Progreso, Moscú.

López Rangel, Rafael (1989), La modernidad arquitectónica mexicana. Antecedentes y vanguardias. 1900-1940. Ediciones UAM, Azcapotzalco, México.

Magnaghi, Alberto (2011), El proyecto local. Hacia una conciencia del lugar. Edicions UPC, Barcelona.

Maldonado-Torres, Nelson (2007), “On the coloniality of being”, Cultural Studies 21, 2 y 3, 240-270

Martínez Andrade, Luís (2013), “Hay que tomarse en serio el pensamiento crítico de los colonizados en toda su complejidad”, (entrevista a Ramón Grosfoguel), Metapolítica 83, 38-47.

Mignolo, Walter (1995), The Darker Side of the Renaissance: Literacy, Territoriality and Colonization. The University of Michigan Press, Ann Arbor.

Ídem (2000), Local Histories/Global Designs: Essays on the Coloniality of Power, Subaltern Knowledges and Border Thinking. Princeton University Press, Princeton.

Ídem (2002), “Colonialidad global, capitalismo y hegemonía epistémica”. En Walsh, Catherine; Schiwy, Freya; Castro-Gómez, Santiago (ed.), Indisciplinar las ciencias sociales. Geopolíticas del conocimiento y colonialidad del poder. Universidad Andina Simón Bolivar-Abya-Yala, Quito.

Montaner, Josep M. y Muxí, Zaida (2011), Arquitectura y política. Ed. Gustavo Gili, Barcelona.

Montes, Angélica; Busso, Hugo (2207), “Entrevista a Ramón Grosfoguel”, Polis 18 (consultado en línea el 12 febrero de 2013. URL: http:// polis.revues.org/4040) 
Moraga, Cherrie; Anzaldúa, Gloria (eds.) (1983), This Bridge Called my Back: Writing by Radical Women of Color. Kitchen Table/Women of Color, Nueva York

Morin, Edgar (1995), "Principios de los cambios sociales del Siglo XX”. En: Morin, Edgar. Sociología. Tecnos, Madrid.

Muñoz, Francesc (2008), Urbanalización: paisajes comunes, lugares globales. Ed. Gustavo Gili,Barcelona.

Muxí, Zaida (2004), La arquitectura de la ciudad global. Ed. Gustavo Gili,Barcelona.

Ortiz, Fernando (2002), Contrapunteo cubano del tabaco y el azúcar. Ediciones Cátedra, Madrid.

Pageau, Christian (2010), “Producción de saberes hegemónicos y periféricos: hacia una apertura del horizonte epistemológico”. Tinkuy 12, 181-197.

Prada, Raúl (2008), Subversiones indígenas. CLACSO - Muela del Diablo - Comunas, La Paz.

Roa Avendaño, Tatiana (2009), “El Sumak Kawsay en Ecuador y Bolivia. Vivir bien, identidad, alternativa”. Revista de Ecología Política 37, 15-19

Quijano, Aníbal (1991), “Colonialidad y Modernidad/racionalidad”, Perú Indígena 29, 11-21.

Ídem (1993), “ ‘Raza’, ‘Etnia’ y ‘Nación’ en Mariátegui: cuestiones abiertas”. En Morgues, Rolando (ed.), José Carlos Mariátegui y Europa: el otro aspecto del descubrimiento. Ed. Amauta, Lima.

Ídem (2000), “Coloniality of Power, Ethnocentrism, and Latin America”, Nepantla: Views from the South, 1, 3, 533-580.

Ídem (2001) “Globalización, colonialidad del poder y democracia”. En AAVV. Tendencias básicas de nuestra época: globalización y democracia. Instituto Diplomático Pedro Gual, Caracas.

Qujano, Aníbal y Wallerstein, Immanuel (1992), “Americanity as a Concept, or the Americas in the Modern World-System”, International Journal of Social Sciences 134, 583-591

Saud, Edward (1979), Orientalism. Vintage Books, Nueva York.

Solá Morales, Manuel (2004), “Contra el modelo de metrópolis universal”. En Martin, Ángel: Lo urbano en 20 autores contemporáneos. Edicions UPC, Barcelona. 
Sousa Santos, Boaventura de (2003), Crítica de la razón indolente. Desclée de Brouwer, Bilbao.

Ídem (2006), Conocer desde el Sur: para una cultural política emancipatoria. Facultad de Ciencias Sociales, UNMSM, Lima.

Spivak, Gayatri (1988), In Other Worlds: Essays in Cultural Politics. Routledge, Kegan and Paul, Nueva York.

Taylor, P. J. y Lang, R. E. (2004), “The Shock Of The New: 100 concepts describing recent urban change”. Environment and Planning 36, 6, 951-958

Toledo, Víctor. M. y Barrera-Bassols, Narciso (2008), La memoria biocultural. La importancia ecológica de las sabidurías tradicionales. Icaria Editorial, Barcelona.

Wallerstein, Immanuel (1974), The Modern World-System. Nueva York: Academic Press.

Ídem (1979), The Capitalist Worl-Economy. Cambridge University Press / Editions de la Maison des Sciences de l'Homme, Cambridge/Paris.

Ídem (1997), "Eurocentrism and its Avatars: The Dilemmas of Social Science”, New Left Review 226, 93-107.

Ídem (2006), European Universalism: The Rhetoric of Power. The New Press, New York.

Weber, Max (2002), La ética protestante y el espíritu del capitalismo. Alianza, Madrid.

Recibido: 05.07.2013

Aceptado: 22.11.2013 